\title{
Knowledge Workers, Identities, and Communication Practices: Understanding Code Farmers in China
}

\author{
Sophie Ping Sun and Michelangelo Magasic
}

\author{
The Chinese University of Hong Kong, Hong Kong, China, sophiesunping@gmail.com
}

Curtin University, Perth, Australia, m.magasic@postgrad.curtin.edu.au

\begin{abstract}
Extending the concept of "knowledge workers", this paper studies the identity dynamics of IT programmers from small companies in China. Through the discursive analysis of programmers' personal memoirs (collected via personal interviews and online ethnography), four themes of identity dynamics emerge: IT programmers demonstrate identification with professionalism and technology; they naturalize the high mobility and internal precarity of their work via discourses of the self and social improvement; the term manong ("code monkey" or "code farmer" in English) is used to support a sense of selfhood amidst high pressure schedules and "panoptic control"; the disparaging term diaosi ("loser" in English) is appropriated in order to activate a sense of self-expression and collective resistance regarding the programmers' working and living conditions. These four themes are integrated into: 1) hegemonic discourses of economic development and technical innovation; and 2) the processes of individualization among IT programmers on a global scale. Our findings suggest that being a knowledge worker means not only to provide professional expertise, communication, creativity and knowledge, it also interrogates questions of survival, struggle, and solidarity.
\end{abstract}

Keywords: Knowledge workers, Identity, IT programmers, CuDA, Manong, Diaosi

Acknowledgement: The authors wish to thank Professor Jack Qiu Linchuan, Professor Saskia Witteborn and the anonymous reviewers for their constructive feedback on an earlier version of this article.

\section{Introduction}

The widespread growth of the global digital economy and IT industries has been the subject of significant academic attention. The workers employed within tasks such as programming and software development, who contribute to the digital economy, have also received attention. Richard Barbrook (1998) has indicated that the digital economy is characterised by the use of new technology and the creation of new types of labour such as the one of knowledge workers. Knowledge workers provide products such as service, information, and ideas as well as the material tasks necessary for the creation of these products (Bell 1976; Drucker 1969; Fuchs 2014; Machlup 1962; Mosco and McKercher 2009). In the context of the information society, in which a significant number of personal, professional and social processes are being digitalised, the role of knowledge workers such as computer programmers in facilitating these activities cannot be underestimated. Knowledge workers play an essential role in the adoption of qualities like creativity, knowledge and communication, into the informational economy (Virno and Hardt 1996) and can thus be seen to form a crucial pillar of economic development.

The authors are far from the first to develop the term "knowledge worker". Substantial work has been done exploring the meanings, implications, and debates surrounding this type of work (e.g.: Bell 1976; Drucker 1969; Fuchs 2014, Machlup 1962; Mosco and McKercher 2009). While the term "knowledge workers" has traditionally been used to reference the intellectual labour of computer-based professions, according to Mosco and McKercher $(2009,23)$ it can also be applied to a broad range of vocations like "university professors, software designers, journalists, call-center workers and united parcel service truck drivers". In his book Digital Labour and Karl Marx, Christian Fuchs $(2014,359)$ analyses a "collective work force 
that is required for the existence, usage and application of digital media" that he calls, "digital labour". Digital labour includes the computer based tasks of programmers and coders, but also encompasses the physical labour of those working to assemble digital devices and those extracting the materials from which such devices are made. Fuchs refers to the multistep labour chain through which digital products are produced as the International Division of Digital Labour (IDDL).

This study aims to contribute to the better understanding of knowledge work by focusing on Chinese programmers working in small companies and their identity constructions. A widely deployed approach in previous studies on knowledge workers' identity highlights programmers as knowledge workers belonging to the middle or upper classes (Das 2001; D' Mello 2006; Ensmenger 2012; Fuller and Narasimhan 2007). For example, Das (2001) regards IT professionals as new middle-class heroes who are responsible for driving India's economic take-off and high flying IT economy. Ensmenger (2012), in his Computer Boys Take Over, indicates the significant roles computer specialists have played in the history of software development. By tracing the history of how "computer boys" established their independent role and identities within traditional hierarchical organisations, Ensmenger emphasises software professionals as a powerful force in modern society. Another coherent research stream exploring computer engineers and their identification is that of technology and hacker culture (e.g.: Kelty 2008; Levy 2001; Thomas 2002; Rushkoff 2010). In the very beginning of computer use in the 1950s, hacker programmers successfully established their "moral code", forming a collective identity dedicated to the free flow of information (Thomas 2002). Empowered by technology and coding, hacker programmers are usually thought of as mysterious, creative and highly technological. In this context, the hacker identity stresses cooperation and collaboration, as well as the innovative and disruptive use of technology (highlighted through examples like open source, hackerspaces, and maker culture). Here, programmers are pictured as a transformative force that can configure and bring about social change (Kelty 2008; Silvia 2014; Weber 2014).

It is not hard to see, either from a class, technology, or cultural perspective, that programmers and their identity are considered as middle or upper class oriented in such research. On the contrary, another research stream holds an opposite narrative analysis with regards to programmers' work and coding practices. It looks at the work performed by computer engineers at the bottom end of transnational production chains and often emphasises high precarity, highly exploitative work practices and the reality of a highly stratified work force within the global IT industry. For example, D'Costa (2002) argues that the development of the Indian software industry is embedded into the development of an uneven and combined Indian capitalism that produces entrepreneurial winners, who accumulate capital at the expense of the mass of digital workers. Drawing on ethnographic fieldwork in India and Australia, Xiang (2007) describes how the flow of international capital dominates the job hunting dynamics of Indian programmers, while adding that the practice of global body-shopping creates uncertainty and precarity in the programmers' working environments. In her analysis of the labour conditions in Foxconn factories, Sandoval (2013) explains that the development of ICT is not only about technological innovation and creativity, but also involves the widespread exploitation of digital labourers whose work is often unstable, alienating and unregulated. The spirit of the current paper is to join these works in the third research stream in exploring knowledge workers in lower social classes by investigating how knowledge labourers perform their social identities in the particular context of small software companies in China.

Knowledge labour performed by IT programmers in China is a worthy area of study. As the world's factory at the beginning of the twenty-first century, China and its massive knowledge workforce play an important role within the processes of global commerce and informationalisation (Sandoval 2013; Xia 2014; Xiang 2007). Over the last decade, Chinese software exports have been increasing at a significant speed. According to a report by the Chinese MIIT (Ministry of Industry and Information Technology,中华人民共和国工业和信息化 部), China's software export value reached 48.7 billion US dollars in 2013 (about $0.51 \%$ of the total GDP). The report also states that in 2013 there were 3108 foreign-funded software 
companies in China with a collective value of 113 billion US dollars (about $1.19 \%$ of the total GDP). Chinese programmers, especially low-level employees, form part of the IDDL as they participate in a transnational labour chain performing outsourced tasks and producing software that is used in international services and business transactions. By exploring the identity dynamics of Chinese workers in small software companies, and connecting these dynamics with social discourses in contemporary China, this study intends to add to our knowledge of the lives, social identities, and discourses of the working class in the information society.

The structure of this article is as follows. First, we discuss the existing literature concerning knowledge workers and the IT industry in modern China. Next, IT programmers' memoirs are analysed to find out how IT programmers perform and maintain their social identities during their work and daily life. The programmers' memoirs are then explained in the light of social discourse in modern China. Finally, further implications concerning our findings on knowledge workers are discussed.

\section{Knowledge Workers}

The concept of knowledge workers has developed significantly since its inception. Fritz Machlup (1962), Peter Drucker (1969), and Daniel Bell (1976) are among the first who developed the concept of the "knowledge worker". Machlup $(1962,267)$ noted that the term refers to either people employed by "a collection of industries producing knowledge" or "a collection of occupations producing knowledge". According to the economist Peter Drucker (1992, 264), the concept of the knowledge worker refers to "the man or woman who applies to productive work ideas, concepts". Bell $(1976$, xvi) did not use the term "knowledge labour", but stated that the "knowledge class" is the fastest growing group in post-industrial society, and that traditional labour theories will be replaced by knowledge value as social production becomes increasingly informationalised.

There may be some narrow differences between these three conceptualisations of knowledge workers, but they converge on the ideas that a) the rapid increase in the number of knowledge workers is brought about by the development of knowledge industries, and $b$ ) that the term "knowledge worker" addresses the production and distribution of information, technology and creativity. Unlike "audience labour" (Smythe 1977) or "free labour" (Terranova 2004), knowledge workers are found in professional occupations and employ specific vocational skills. Kleinman and Vallas (2001) imply that the very term "knowledge worker" indicates a process or a class distinction, in which knowledge and expertise are more esteemed than other types of work. Janz et al. $(1997,878)$, who describe knowledge workers as relatively "high-level employees", support this distinction. Such workers can apply their knowledge to develop and design new products or services. Indeed, while many previous definitions of the knowledge worker perceived knowledge labour as diametrically opposed to physical labour (See: Drucker 1992), recent explorations see knowledge workers as being composed of a vast range of professions, including those that include physical tasks.

Vincent Mosco and Catherine McKercher (2009, 24-25) maintain that the definition of knowledge labour should not be confined to professionals only and should include any labourers that "handle, distribute and convey information and knowledge". Building on this understanding, Fuchs (2014) argues that digital labour is characterised by industrial rather than occupational dimensions, that is to say, any activities which contribute to the digital economy can be seen as digital labour regardless of their specific occupational labels. By making this assertion, Fuchs seeks to highlight the diverse range of occupations involved within the digital economy, the connection of labour processes which might otherwise appear distant and the unifying effect that digital labour has on different workers around the world (i.e. the IDDL).

In terms of research on engineering, the juxtaposition of programming labour and manual labour generates a seemingly contradictory analysis model within the conceptualisation of knowledge workers (Downey and Lucena 1995): On the one hand, computer engineers can be seen as a powerful group due to their mastery of technology. On the other hand, engineers may feel powerless and marginalized since "a microworld can become a challenging arena for an adult quest for power and control" (Edwards 1996, 172). Hacker (1989; 1990) 
claims the pleasure and the sense of achievement software engineers derive from their work is closely related with the power they hold. Florman (1976) echoes Hacker's analysis by noting that for engineers, technology can be seen as a symbolic power that extends their limited sense of potency. Through working as a group, programmers can then reproduce patterns of homosociality and form a collective identity (Deetz 1995; Mellström 1995; Murray 1993). Valk and Srinivasan $(2011,44)$ indicate that women IT professionals value their role as programmers, and defend their identity through terms like "challenge, accomplishment, morale boost, satisfaction of using skills, drive to explore, drive for self-development, growth as a person, and personal satisfaction derived from work".

On the other hand, a body of critical research on IT professionals contends that programmers' work experiences are not always positive. Academic studies have shown that programmers frequently experience precarity and risk. Arora et al. (2001) conducted research on the Indian software industry and concluded that Indian IT workers are in a disadvantaged position since they tend to conduct simple and repetitive outsourcing work for corporations in Western countries. Xiang $(2007,5)$ shared this opinion in his "global body shopping" study, indicating that "body shopped" Indian programmers undertake "donkey work" and receive a rather low salary. In a Chinese context, Xia's (2014) ethnographic study indicates that most Chinese Internet workers reside in the lower middle class and suffer from high exploitation as tiny cogs in a massive global system.

\section{ICT and Manong in Modern China}

Although a latecomer to the digital economy, the development of the Chinese ICT industry is already quite expansive. Furthermore, as a result of the current climate of economic growth in China, the Chinese ICT industry has experienced significant expansion in recent years. According to the OECD Outlook database (http://www.oecd-ilibrary.org/), China has established itself as one of the most important countries for the production and use of ICTs. From 2004 onwards, China has been the biggest exporter of ICT products, which is due to its role in assemblage and manufacturing, whereas software is not such a major part of the Chinese ICT industry as it is in other countries. In 2013 , its exports accounted for $27.4 \%$ of the worldwide total. While using the wide frame of the Chinese IT industry, this project will focus its investigation specifically on workers within the Chinese software industry. Generally speaking, the software industry involves software products and software services, including development, marketing, sales, and maintenance. Its product scope is rather extensive including operating systems, computer/laptop applications, network management tools, and various enterprise or personal programs. Spurned by the dramatic expansion of the IT market in China and worldwide, the software industry has become the fastest growing section of the Chinese IT market. Based on the report of Gartner (http://www.gartner.com/), at the end of 2013, the total market size of the global software market totalled 350 billion US dollars $(0.46 \%$ of the global GDP)..With the growth of the software market as well as Beijing's continuous focus on informationalisation in all walks of life, including e-governance, information monitoring, stock market trading, logistics and online shopping, China can be seen to be in the stage of building a vast software empire. 


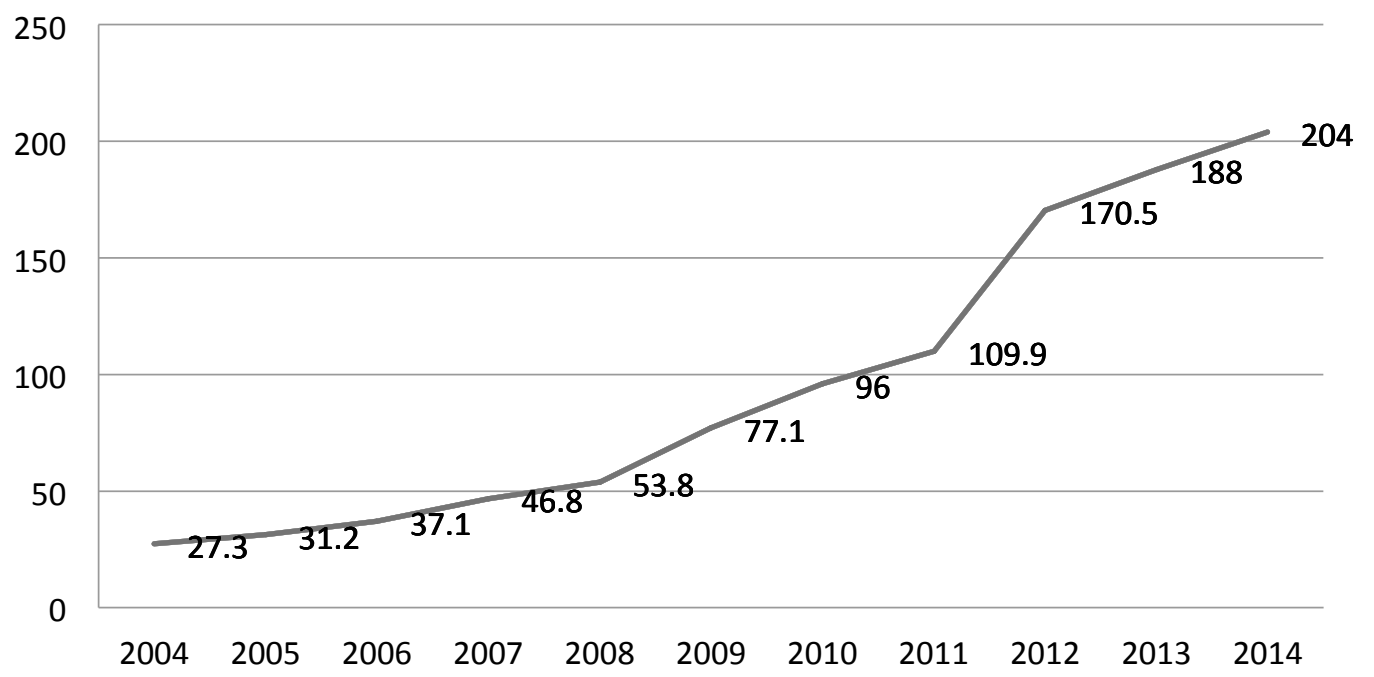

Figure 1.1: Growth of ICT market output in China in billions of USD, by year-end data (Data source: IDC Research Report (2004-2014))

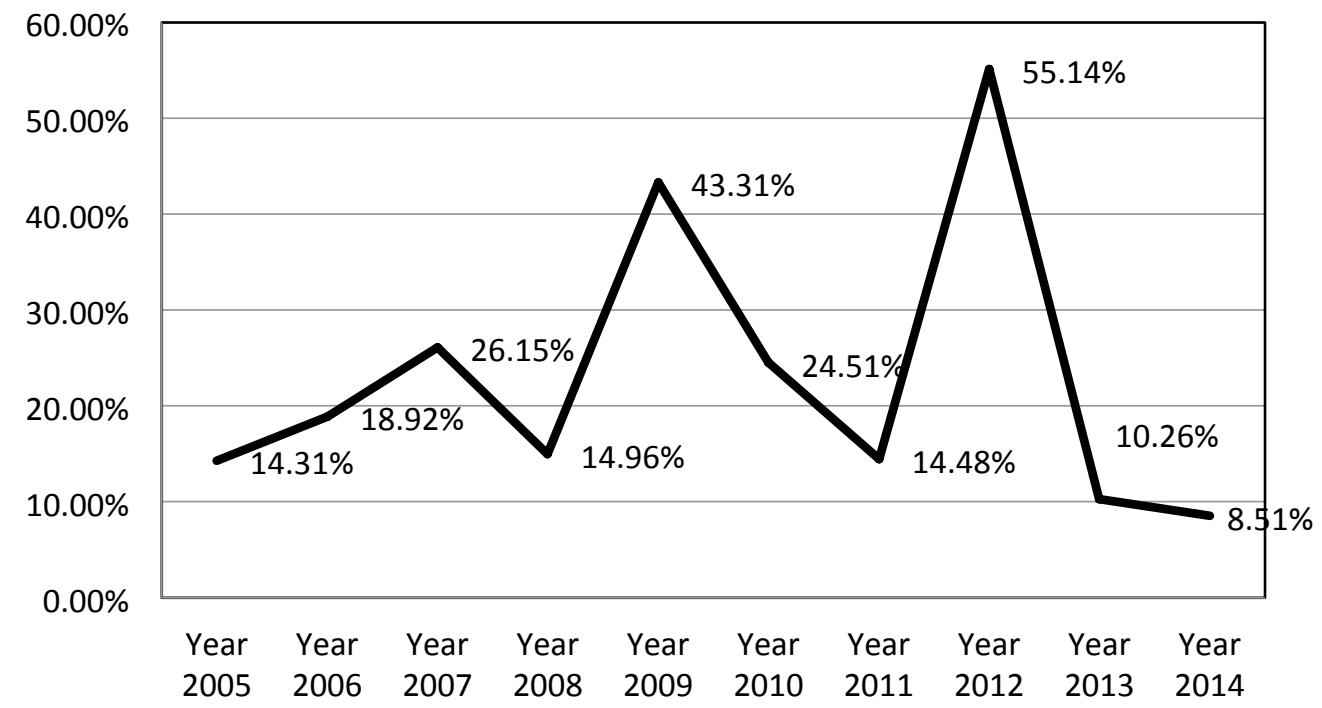

Figure 1.2 Relative growth of the ICT market output in China, in percentage by year-end data

(Data source: IDC Research Report (2004-2014)) 


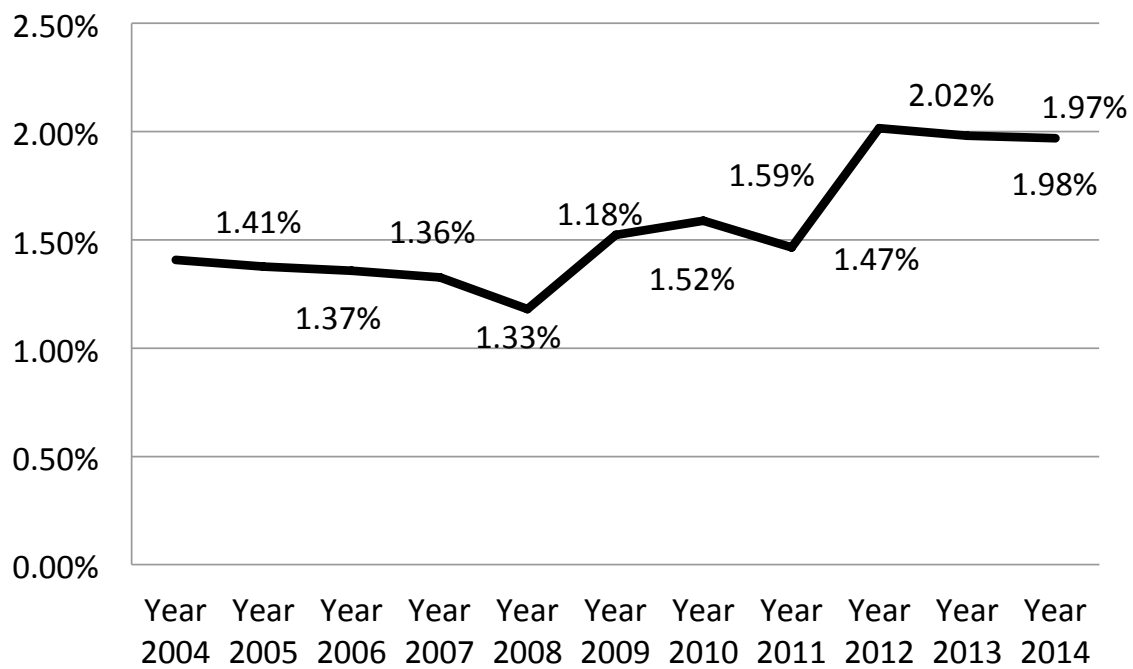

Figure 1.3 Share of the ICT industry's output in the Chinese GDP, in percentage by year-end data

(Data source: IDC Research Report (2004-2014))

In China, many different levels of software enterprises, co-exist including domestic giants like Baidu and Tencent, large foreign owned companies like Microsoft, joint venture companies and varying tiers of smaller domestic companies. In 2014, there were 37,102 software companies in China with 6,183 new companies entering the market between 2013-2014 (MIIT, 2013). This environment of prosperity is buoyed both economically and socially by the emergence of giant Chinese IT companies like Tencent (“腾讯”), Huawei (“华为”) and Alibaba (“阿 里巴巴”), which has also fostered a new generation of rich entrepreneurs and professionals, like Jack Ma (馬雲), the founder and CEO of Alibaba Group; Pony Ma (馬化騰), the founder of Tencent Inc., as well the "Musketters of the Internet", William Ding (丁否), Charles Zhang ( 張朝陽) and Wang Zhidong (王志東). They have become kind of ideological hero entrepreneurs in China.

However, there are two salient differences between the Chinese and Indian software industries. Firstly, compared with India's software industry, where outsourcing and offshore production account for a considerable percentage of India's IT industry as a whole (Fuchs 2014), China's software industry takes on a slightly different form. In China, most IT work is performed for the domestic market rather than for offshoring or exporting (MIIT 2013). However, as many of the software companies that cater to the Chinese market are joint ventures or foreign owned, there is still sizeable foreign investment within the Chinese software industry. Moreover, outsourcing does still form a valuable component of the Chinese IT industry. In order to reduce their labour cost, Western companies outsource coding and testing work also to software companies in China. This outsourcing work first goes to big companies, and then those companies dispatch parts of it to smaller companies, resulting in a hierarchical structure, in which the most repetitive and laborious tasks are largely borne by the smallest software companies. Thus, thousands of small software companies in China are involved in the lower end of the global software production chain.

Secondly, compared with Indian programmers, who are usually overeducated for their job (Upadhya and Vasavi 2008), programmers in China face a different situation. While in India and the West software professionals have been described as the new middle class who are mostly well-educated, professional, qualified and technical (e.g. Fuller and Narashimham 2007; Das 2002), according to the 2014 The Electronic Information Industry Statistics Yearbook of China (MII 2014), in 2013 more than 40\% of Chinese workers in software and engineering were trained at vocational schools (see figure 2). In vocational schools, students receive training for anywhere from a few months to two years, and then become low-level 
programmers or 'manong' in small Chinese software companies. While the majority of Chinese software engineers do in fact hold a Bachelor degree, it is worth noting here the rigorous hierarchy, in which Chinese universities are ranked. Potential employers see "211" or "985" universities as much more appealing than other institutions. There are no official statistics on the educational backgrounds of software programmers in different levels of companies, but a degree from a "211" or "985" university (which account for less than $5 \%$ of the total number of universities and colleges) is considered the benchmark for entering big IT companies like Microsoft, Alibaba, Baidu or Tencent. Thus, many graduates from lower ranked universities often end up working unappealing jobs in small companies.

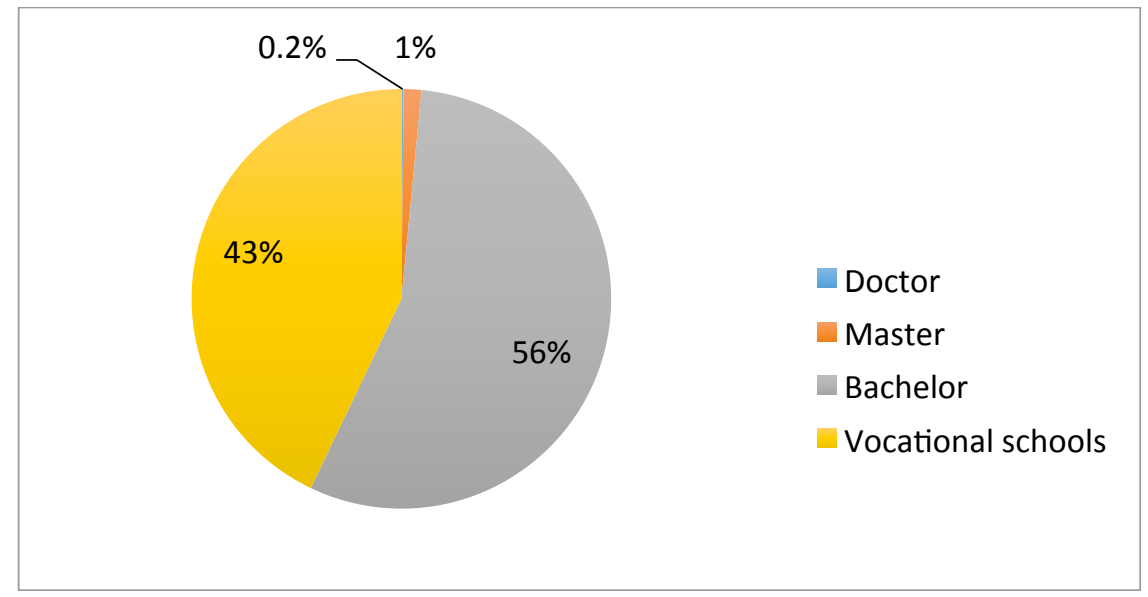

Figure 2: The Educational Background Structure of Software and Engineering Graduates in 2013 (MII 2014)

The International Division of Digital Labour, the Chinese domestic IT industry structure, as well as the educational background of programmers lead to a hierarchical distribution of programming labour. China does have a labour aristocracy of upper class software workers (Engels 1892; Fuchs 2014), like the engineering professionals working for multinationals or big domestic companies such as the BAT trio (Baidu, Alibaba, Tencent). They are programmers who are well educated and gain a higher salary, but they only account for a small part of the programming army in China. According to Yue (2015), above $90 \%$ of the programming labour in China works within small software companies, in which the total number of personnel is less than 100. It is interesting to see that some lower end Chinese IT programmers working in these small companies use the term manong to identify themselves or describe colleagues. The term manong was itself coined by low-level programmers in China in order to characterise their repetitive coding work and poor conditions. Owing to the extensive use of humour and vivid expressions commonly employed within Chinese Internet platforms, the term soon gained usage as a collective name of all IT programmers in modern China. In English, manong's meaning can be literally translated as "code farmer", with its meaning being similar to that of the slang term "code monkey". As time has passed, manong has become a collective name conflating various kinds of software developers, computer programmers and IT professionals. While job titles and positions may vary in different companies, the main work manong conduct involves writing, testing, and debugging programmes that computers follow to perform different functions.

For this study, the researchers took small private software companies in the cities of Beijing, Shanghai and Shenzhen as our study subjects. The rapid growth of small Chinese software companies is a relatively new phenomenon and their prosperity helps to attract the majority of computer programmers and ICT workers in China. Compared with giant companies like Tencent, Alibaba and Baidu, small companies are characterised by their modest size (usually less than 100 workers) and flexible operations. Usually they are located in the prosperous high-tech centres of big cities such as Beijing Zhongguangcun Technology Park, Shanghai Zhangjiang Hi-Tech Park or Shenzhen Nanshan Hi-Tech Park. These firms' main work con- 
sists of developing software platforms for other non-IT companies or undertaking outsourcing projects from big software companies. In order to survive in this highly competitive environment, the firms usually hire a small number of staff and perform a wide range of developing tasks. The bulk of computer programmers in China are young people, who migrate to big cities from rural China. A small minority of programmers are well-educated career programmers, but most are young and not-so-well-educated (See: Figure 2). IT programmers contribute a lot to the rapid development of the digital economy in China, but have thus far not been the object of much academic research. Questions like how Chinese programmers in small companies define and understand themselves and what roles they play as knowledge workers within the global IT industry remain unanswered. Based on the lack of research concerning knowledge labour within China, this paper addresses the following research questions:

1. How do IT programmers perform their identity as knowledge workers?

2. What does it mean for IT programmers to be manong? How does this status relate to their identity as "knowledge workers"?

3. How does the experience of manong IT programmers in China confirm or extend the results of existing research on knowledge labour?

\section{Methodology}

We have employed cultural discourse analysis (CuDA) in this study (Carbaugh 2007). Cultural discourse is conceptualized as "a historical transmitted expressive system of communication practices, of acts, events, and styles, which are composed of specific symbols, symbol forms, norms, and their meanings" (Carbaugh et al. 1997). CuDA is a relatively new approach that helps to explore how sociocultural life is created and maintained by communication and interaction. This method asserts that communication both assumes and constitutes social realities, in which identity, relationships, emotions, actions and dwellings represent particular areas of focus (Carbaugh 2007). Situated within the increasingly connected environment of the digital economy, knowledge workers characterise themselves through the employment of intelligence, innovation and language (Marazzi 2011). Concomitant to their technical expertise is the frequent use of language and communication during job tasks. Marazzi (2011) has noted that information flows and communication practices are an indispensable part of the way knowledge workers express their identities. For cultural analysts, the communicative acts that take place during knowledge workers' quotidian work lives also contain elements that express broader concerns such as who they are, what they believe in and why they behave in a certain manner. In that sense, we believe that knowledge workers' communication practices are effective and efficient facilitators for us to explore their daily relationships and sociocultural preferences.

In this study, we aim to look at the specific culture of computer programmers and the social behaviours inherent to this group on both a personal and professional level. Thus, in our research, culture refers to the sociocultural meaning Chinese programmers have created by being, identifying, relating, and acting as knowledge workers. We argue that the communication practices of programmers actually are the meaning and complexities of being, identifying and acting as knowledge workers. In the analysis of programmers' communication acts, we treat meaning as an imminent, spontaneous part of communication practices.

We have collected data through in-depth, semi-structured interviews with computer programmers as well as through online ethnography. We interviewed 26 employees from 10 small companies in Beijing, Shanghai and Shenzhen. The interlocutors included 6 females and 20 males. Each interview lasted from 60 to 90 minutes. The data was collected in March, May and November 2014, when one of the authors went to Beijing and Shanghai to conduct these studies. The same author also went to Shenzhen three times to talk with the programmers who work there. The interviews started with the researcher telling the interviewee the purpose of the study and providing a promise of confidentiality. The interviewees also provided informed consent. Some important questions like, "Why did you want to be a pro- 
grammer?", "Do you think of yourself as manong?", or "Tell me one impressive thing about your work", were asked in order to explore the respondent's identity dynamics and the implications of being a manong in the Chinese ICT industry. Instead of a strict structure-based interview, a set of open-ended questions concerning the respondent's personal experience, work projects, and daily life in and outside of work were asked. In addition, the interviewer also went to Shenzhen to visit some of the programmers' houses and working places, and commuted to work and back with them.

The authors also used online ethnography as a compensatory method to collect data. Online ethnography is a method used to explore the communities and cultures of computermediated interaction. This method understands the Internet as both a culture and context for social interaction (Dominguez et al 2007). Online ethnography is an appropriate method for our study given programmers' occupational and collective characteristics. Research has shown that computer programmers have a higher frequency of Internet use than average. They on average spend 41.5 hours per week in front of a computer at work (CNNIC 2014). Moreover, programmers are apt to spend the majority of their free time surfing the Internet. Consequently the Internet becomes the second home for many programmers in China, as is evidenced by the burgeoning programmer bases on some BBS, online communities, and websites. Baidu BBS (tieba.baidu.com), Zhihu (zhihu.com) and Guokr (guokr.com) are among the online communities that host large numbers of programmers. Compared with some professional online communities like Github (github.com) or Google Code (code.google.com), where open source coding is discussed and code is shared, Baidu, Zhihu and Guokr attract thousands of programmers who communicate not only about technical matters. but also about their daily life and work experiences. Baidu BBS is one of the biggest discussion forums in China. Zhihu and Guokr are among the most popular Q\&A network communities. Particular forums entitled "IT workers", "Manong" or "IT programmers" are created within these online communities as places where stories, emojis and casual dialogue can be shared between IT workers. The multidimensional conversations that occur there, constitute, as Carbaugh $(2007,174)$ has indicated, an important cultural discourse about the programmers' "personhood, relationships, actions, emotion, and dwelling". Based on this, we argue that online ethnography is an efficient and useful way to explore how programmers develop, distinguish and maintain their identities.

Communication practices in $Q \& A$ conversations and discussion board posts are common formats in Baidu BBS, Zhihu and Guokr Q\&A websites. The researchers registered on these online communities in order to collect data through online observation, participation in discussions, and interaction with other members in Q\&A format. One of the researchers has already been a member of Baidu, Zhihu and Guokr for more than two years, so we were able to draw on this experience when analysing online communications. The total number of registered participants in these programmer groups can be found in Table 1.

\begin{tabular}{|c|c|}
\hline Programmers' Online Communities & Number of Members \\
\hline Baidu Post Bar & 24,854 \\
\hline Zhihu Q \& A Community & 22,054 \\
\hline Guokr Q \& A Community & 15,931 \\
\hline
\end{tabular}

Table 1: Registered members of relevant websites (Note: Retrieved November 28, 2014.

(No. of members refers to the number of people who have registered as a member) 
Both the logs of our interviews and the information retrieved using online ethnography occupy the genre of memoir, as these are personal narratives about salient concerns within the subject's lives. These thoughtful reflections serve as testimony through which the researchers can observe the experience of knowledge workers from the perspective of people living within this world. A memoir presents a highly personalized "insider view" (Boylorn 2008, 505) that is redolent of the tapestry of small, everyday details that make up the respondent's social reality. It provides a discourse that, in its original state, is not presumed upon by the researcher's ways of knowing. As Scott $(2014,760)$ argues: "Memoir writes the personal story, without the theory". It is exactly this academic impartiality and attention to personal significance that makes the memoirs a fertile resource for investigating the identity dynamics of Chinese programmers. All of our data was coded in Chinese and later translated into English when conducting the analysis. During both of these events, the researcher must be mindful not to transmute the respondents' meanings (Maniam 2014). Despite these challenges, memoir provides a suitable lens through which to explore the communication practice of Chinese programmers and the "meta-cultural commentary" (Carbaugh 2007, 168) that accompanies this: the good aspects of programmers' lives, the bad ones, and how life experience varies between individuals.

\section{Professionals, Socially Constructed Meritocracy and Identification}

Throughout this study, a sense of "technical pride" was frequently expressed by the programmers. One example can be seen in a response by interlocutor $A$, who recounted the sequence of events, by which he came to work in the IT industry:

"When I went to university, I majored in journalism. Then I switched to information technology and learned ' $\mathrm{C}++$ ' [one of the programming languages]. I feel so lucky to have done that. I just love the computer languages because compared with journalism, you can actually learn a lot more from IT: you get a smarter mind, and a more promising future. I think the IT industry is the brightest one among all the industries in modern China, right? I feel very motivated when I realize I am one of the technicians in our IT industry."

A's sense of belonging and positive identification as an IT programmer come from the fact that he perceives himself as somebody who possesses in-demand technical skills and works within an avant-garde industry. Wrapped up in this identification are narratives on programming languages such as " $\mathrm{C}++$ " and an overt sense of achievement expressed in phrases like "learn a lot more" and "a smarter mind". In A's memoir, he mentions the high standing of the IT industry in modern China and relates this to his own position. Indeed, A is not alone in his choice of phrases and images. While less celebratory than A, Interlocutor B, a software developer who has been working in the industry for 2 years, relates similarly positive statements about the growth of the IT industry both in China and worldwide:

"Being a manong is not the best vocation, but it is not bad either. At least you can make a living from using a technology you have mastered. Not everybody can say they make a living utilizing a particular skill. I do not mean to offend, but we are the experts on computers and software. The IT industry is taking off, both in China and in the world. My salary is ok, and using your skills, you can have a decent life and promising future."

Beyond his strong identification with technology use and the rising IT industry, B's narrative highlights social stratification in the class structure. Despite the somewhat perilous position he claims to occupy within the middle class, B seems happy to belong to a social group whose talents are in demand. Moreover, $B$ is pleased to be able to support himself using a particular skill that he has invested time in to learn and master. Thus, both respondents can be seen to indicate a sense of pride in their work as they foreground the acquisition of useful technical skills and the contribution these make to the growing IT industry. Actually, while 
relating their experiences working with information technology, both A and B's statements challenge traditional ideas about labour. Talking about their lives as IT professionals, the respondents' strong identification with technology and frequent references to modernity, mask their labour processes and working reality. A similar challenge was also found in the responses of female programmers, who recounted that, while male dominated, the IT industry offers skills, opportunity and, potentially, a burgeoning meritocracy between male and female workers. Interlocutor $\mathrm{C}$, a female Chinese programmer explains:

"When I introduce myself, I am proud of being a programmer. I mean, especially when you are a girl. When I meet some new friends and they know I am a computer programmer, and that I can also use 'Java' and '.NET' (two computing languages), they look up to me. In a field where men are dominating, girls are valued."

In traditional Chinese culture, work is central to male identity. The increased participation of women in the IT industry has brought new dynamics and implications to IT work culture. Mukherjee $(2008,64)$ indicates a similar process within Indian popular culture where the IT industry portrays an appearance of meritocracy and accessibility: "popular journals are replete with stories about the 'high techlift to middle class Indian women', emphasizing that this industry is ideal for women because it does not involve physical or manual labour but intellectual labour".

Mirroring this process of female IT workers' gaining opportunities through technical skills, C's response indicates that she receives social status because of her knowledge of computer languages. C's achievements do not, however, mean that women as a group are not confronting questions and challenges about their skills and use of technology, especially against the background of the gendered status of technology and computing languages (D'Mello 2006; Mukherjee 2008). For a long time, females were excluded from male-dominated industries such as engineering, IT and science. With the help of education and the breakdown of traditional limitations on female career paths, increasing numbers of women are becoming programmers. Thus C's identification as an IT programmer indicates a socially constructed process, in which gender takes an important role in contextualizing the individual (as an ambitious go-getter) and the overall growth of the IT industries (as supported by new labour demographics such as young female programmers).

Through personal narrative, the individual situates oneself in a particular position, in which personalised sociocultural and political identities form (Witteborn 2008). During our interviews, the respondents' sense of belonging regarding technology was socio-culturally meaningful in constructing their identity as IT programmers. Despite, or perhaps because of, the historically gendered status of technology and computer languages, technical pride is particularly notable in female IT programmers, and it helps to construct a sense of meritocracy among IT programmers. Instead of using terms associated with arduous labour, respondents' work tasks are represented by more "fashionable" associations like the names of computing languages and technology, statements about professionalism, as well as references to the overall growth of the IT industry. The programmers' responses also foregrounded the relationship between the individual and their wider social context. Given the respondents' frequent references to the esteem, in which their job was held, it can be said that Chinese IT programmers see themselves as contributing to the growth and advancement of China as a whole, at the same time as participating in their own self growth.

\section{Places, Mobility and Internalised Precarity}

A high degree of worker mobility is another salient point that emerged within our data analysis (See: D'Mello and Sahay 2007; Xia 2014). When individuals relate their work experience, they often use expressions such as the following ones: "I have worked in Beijing, and now I am in Shanghai", "I used to work in Shantou, but I went to...", "I worked there for three months, then I went to another company". The vast majority of interviewees had experience 
working in multiple companies or cities, while some also took part in projects that operated among different cities, provinces or countries.

If being an IT programmer involves high mobility and liquidity, what then does mobility mean to IT programmers? According to interlocutor D, frequent job-hopping is, "a normal part of being a programmer". He explains the need for job-hopping by addressing his personal development within the context of the fast moving, ever changing IT industry in China. D is an IT programmer who is responsible for developing online transaction systems. He works in Shanghai, but must frequently visit another six cities in order to participate in different projects. The geographically dispersed places he visits form a "migrating map", in which IT programmers are "high tech nomadic workers" (Upadhya and Vasavi 2008, 20). ledema et al. (2005) indicate that due to the increasing intensity of communication and the high mobility of information, modern management requires knowledge workers to respond and act faster and faster, making their professional life constantly mobile and fluid. Perhaps it is accurate to say that it is these same occupational characteristics that make IT programmers frequently relocate to different physical places. However, the underlying mechanism here is a highly mobile market and capital (see: Xiang 2007). Labour is increasingly tied to this mobile capital but has little control over it. As such, the growth of the networked IT industry in modern China results in the increasing disembodiment of programmers. Acknowledging the social consequences of the information society on the bodies of physical workers, other pertinent questions are brought forward such as how IT programmers identify with the high mobility of their work. And, how do they deal with the precariousness and risk of being an IT programmer?

Another comment on the mobility of IT programmers comes from interlocutor E, who shared her working experience with us:

"I graduated from Wuhan and worked in a company for 2 months, then I went to Shanghai. It is a good job, but actually I found anyone else could do the job I was doing-it was not creative at all. I felt futureless. That's the reason I came to Shenzhen... Usually your income will increase $10 \%$ or more if you choose to go to another company. What's more, most of us (IT programmers) can have a better opportunity for individual development if we change to another company, right? No one is stupid enough to change companies if the next job is worse. Frequent job-hopping is often the case. The IT industry in China is changing so fast, you have to keep learning new things, and nobody knows what will happen in the future".

During the interview, the interlocutor cited a number of different cities, in which she had lived in combination with phrases like, "better opportunity", "changing so fast", or "keep learning new things". Within her memoir, personal development is an important element that she balances with potential risks. In that sense, the insecure and precarious traits IT work holds are subsumed into the "discourse of achievement", in which all risks become integral parts of an individual's success. As such, the unstable job security of her work has been internalised as a natural and normal phenomenon. In the memoir above, we can also view the previously mentioned narrative type, in which the respondent relates her personal development to the context of wider society. This narrative sequence, combining individual development and outer risks, informs the specific dynamics of how IT programmers identify their mobility and job security.

In regards to our first research question about the ways, in which IT workers distinguish and maintain their identity as knowledge workers, we may conclude that IT programmers manifest themselves as knowledge workers through their identification with professionalism, technology, meritocracy, mobility, and precarity. They frequently address technical skills and the mastery of programming languages. Coding skills are seen as an integral part of being an IT programmer. Programmers also take their highly mobile, precarious work conditions as normal, regarding these circumstances as a natural part of how IT works. Here, individual development is seen as an important motivating factor for the internalisation of the precarity involved with frequent physical mobility. 


\section{Deskilling and Panoptic Control}

Much scholarly attention has been given to the new "creative class" that post-industrial information society has brought about. Within this domain, IT industry workers are given labels such as "professionals", "programming scientists" or "technicians" and are commonly pictured as performing highly skilled tasks (See: Janz et al. 1997; Florida 2002; Shirky 2010). However, we found that much of the work performed by our respondents, especially IT programmers in small companies or in the initial stages of their career, is highly mechanical and unskilled. One example is from interlocutor $F$. $F$ had only recently graduated from a technical training school called Bei Da Qing Niao, and found a job in Guangzhou.

"It is the lowest of the low to become a programmer. What you need is to find a training institution and learn one or two years hard. You get skills that companies need, then you work for them. They do not care about your programming languages or your quality or anything else. What they want is that you do the work as quick as you can. That's why we call ourselves "manong". We are like construction workers, and the difference is that they deal with bricks, we deal with code. Both are boring, repetitive work."

In Chinese, manong can be translated as "code farmer" or "code monkey". In stark contrast with celebratory rhetoric about the new "creative class" and the imagined prestige of virtual labour, what interlocutor F emphasises is that being an IT programmer is no more than a grapple with survival. F employs descriptions such as "repetitive" and "lowest of the low" and the metaphor "construction workers" in order to highlight what he perceives as the bleak reality of programming. $\mathrm{F}$ also goes as far as to explode beliefs in technical prowess or work quality as are espoused in positivist views of knowledge workers or the 'creative class'. Another example which further illustrates the deskilled working context of programmers can be seen on the Baidu BBS. Within this platform, there is a discussion group especially for IT programmers called "Programmers' Bar" with communication here taking the form of a Q\&A:

"Question: It seems that computer programmers suffer from poor working conditions, but I can do nothing except writing codes, what should I do?"

"Answer 1: There is a famous saying, "easy come, easy go". So it is with us computer programmers. We are like disposable chopsticks, becoming useless as soon as the company stops employing you. You undertake a four-month training, and you become a computer programmer. Then they (the companies) bleed you dry. You are absolutely like rubbish. Such is the life of being a manong."

"Answer 2: Tell me about it. Computer programming is for young people only. You work for several years then it is all downhill. This is the law. You have to keep learning new things. [...] I know a friend who develops C\# (a computer language). He works from 9:00 a.m. to 10:00 p.m., and sometimes he works till dawn. He eats, works and lives in the company, 3000 RMB per month (Approx. \$500 US). His hair is falling out badly."

"Answer 5: Think about why you want to become a manong. For money? For enjoyment? If it is so, then you should definitely change your job. [...] Look at China, it is such a big country, but we even don't have our own Spring Frames (a kind of simplified programming language framework), let alone languages, data and operating systems. Our society is too impetuous."

The answers above show the plight of being a computer programmer in China. The programmer's life is characterised by hard work, long hours, low pay and poor job security. Our interview material evidences this circumstance by the use of metaphors such as "disposable chopsticks" and "bleed you dry". As McKercher and Mosco (2008) have indicated, there is a 
process of deskilling among many knowledge workers in the digital economy. Though they are called "knowledge workers", much of the work of our respondents is monotonous and repetitive. In recent years, one of the characteristics of the burgeoning IT industry is outsourcing. Outsourcing occurs when a big company sends parts of their non-core but labourintensive business to small external corporations in order to reduce their production costs. In the highly competitive Chinese economy and IT industry, taking on outsourced work has become an important means of livelihood. Usually this kind of work is low-paid and timeconsuming. However, both big and small companies are benefiting from reducing the skill components of IT programmers.

In couplet with these narratives of deskilling is the overall scenario of hyper-pressure and highly exploitative working conditions that the programmers face in and that appears entrenched within the IT industry. IT companies develop both "hard" and "soft" management strategies to control their workers. IT programmers are usually asked to finish the project as soon as they can, and once they get involved with a project, intensive communication is conducted between them and their module leader, project leader, and project manager. Interlocutor $\mathrm{G}$ explains:

Every afternoon, we have a corporate meeting. We are asked to report on the work we have done that day to the module leader. Then he will report it to the project leader. The manager will not intervene with our work directly, but he has a good idea of what you are doing and what you have finished, and of course, not finished. But actually it is not as strict as you imagine. The managers often invite us for dinner, and we are also offered drinks and snacks during the break. [...] We have a fingerprint checking system, and if you are late, it will deduct 50 yuan (Approx. \$8 US) from your salary. But most of the time, the money we have been deducted is used for our project dinners or parties.

$\mathrm{G}$ is not alone in having such work experiences. In most companies, IT workers are expected to perform as individualised, self-managed employees while at the same time, "they must perform within a tightly controlled and impersonal management system that traces their every move and moment" (Mukherjee 2008, 65). In the interlocutor's response, this rigorous, Taylorized control is achieved by management strategies evidenced by phrases such as everyday "reports" to the "manager", "fingerprint checking system", salary reduction "if you are late". Such Taylorist control presents itself as humane and tries to hide its exploitative nature by employing "dinners and parties" as the reward to its employees. IT companies like to create a "lively, friendly, and harmonious" (Upadhya and Vasavi 2008, 31) environment, and they give their workers material incentives to stimulate their activity. Under these conditions, a "panoptic" environment is formed, in which managers totally control workers (Bentham 1791; Foucault 1977). While on the one hand, employees are subject to the high pressure of their work, we find the gaze of their supervisors and constant progress checks on the other hand. They feel attracted by their workplace and the social engagement and camaraderie it offers. Within such a space, the boundaries between work time and spare time, labour and play, become fuzzy (Fuchs 2014). That workers should have fun and, as such, enjoy (or at least accept) the repressive controls emplaced upon them, has become a new ideological strategy of capital. In such conditions, the "panopticon" becomes the IT workers' "internal gaze of self" (Upadhya and Vasavi 2008, 30). This internal gaze leads to the term manong as the most appropriate one to address their selfhood as labour 2.0. Not only do they work under tough conditions, but in the digital work site surveillance and progress monitoring are nearly always present.

\section{Manong as Diaosi: A Challenge to Hegemony}

Identity issues connected to diaosi (“帛丝” in Chinese) are popular among computer programmers. Diaosi in Chinese is a self-deprecatory term that refers to people, especially 
males who are part of the lower class and suffer from poor working conditions. This term gained its popularity on the Internet in 2011. Now, it has become a catchword amongst the salariat and blue-collar workers. IT programmers are among the different social groups that refer to themselves as diaosi. For example, interlocutor $\mathrm{H}$ said in Baidu BBS:

"I was born in 1985. I took the National College Entrance Examination three times, so I am two years older than my classmates. I didn't find a job after I graduated from college, instead I lived off my parents. One year later, I became a computer programmer. I have been working for two years, and now I earn 3,000 RMB (Approx. \$500 US) per month. I feel futureless and unmotivated [...] I'm almost 30 years old and I have no girlfriend. I have nothing. Now I am exactly a diaosi."

H's memoirs focus explicitly on the poor working conditions he is confronted with. He identifies himself as diaosi by stressing that he is old, poor, and hopeless. In this situation, being an IT programmer doesn't ameliorate his poverty. $\mathrm{H}$ is not alone in identifying himself as diaosi. Another example can be found in a Zhihu Q\&A community entitled "Diaosi IT Programmers":

"Question: I am a diaosi code monkey, and my monthly income is less than 10,000 (RMB). My girlfriend wants us to get married before she turns 30, but I have no money to do this, let alone to buy a house or a car. What can I do?"

"Answer: Let me first introduce myself as well. I am from Shijiazhuang, and I am an IC computer programmer. I graduated from a low-level college and I got a Master's degree at a 211 university [...] My family is poor, and my parents are old, I have no car, no house. I am a diaosi, too. I was despised when hunting for a job. I cannot find a chance in Shijiazhuang, but I also cannot leave my parents alone. Coding is boring and arduous, and I make little money. I am killing myself."

In this Q\&A exchange, diaosi is related to low income, high pressure and confusion - all elements that cause computer programmers suffering. As such, it is interesting to find that many IT programmers willingly identify themselves as diaosi, and that even some female IT programmers call themselves "female diaosi". Diaosi has become a shared, collective symbol among the manong and a variety of emoji, comics, and memes have been created in order to give expression to this term and its shared signification. Upadhya and Vasavi (2008) indicate that Indian software engineers show "a central feature of individualization" (24) and lack a collective identity as workers or employees. However, we argue here, the expressions of manong and diaosi in modern China can be regarded as a collective identity. The highly precarious, mobile, deskilled working conditions endured by IT programmers, create a sense of liquidity, uncertainty and anxiety. The term manong captures this labour. From this point, the catchword "diaosi" has developed as a means to seek self-expression and selfawareness. While the usage of the term manong is almost literal in meaning, diaosi's signification is figurative and as such lowlier, sharper, and more alarming. Li and Li (2013) have indicated that diaosi culture is recreational and ironic, but it is also collective and critical. In this way, IT programmers use diaosi as a shared expression to challenge the inequality, precarity and alienation inherent in their position as knowledge workers.

Regarding the second research question, the identity of manong is enacted alongside expressions describing hyper-pressure, deskilling as well as attempts at resistance. Lazzarato (1996) notes that one of the primary characteristics of knowledge workers in modern management is the integration of work and subjectivity. Within that mechanism, institutional control over labour expands from work completion to subjectivity construction that includes activities traditionally outside of the work sphere such as communication skills, creativity and knowledge. Through the memoirs of the respondents, we can see that Chinese IT programmers have experienced a process of alienation: They are engaged for long hours in repetitive work, and the borderline between working time and personal time has been made indistinct 
by corporate strategy. While knowledge labour occurs within the discourse of the 'creative' informational economy, only a minority of the programmers surveyed by this study situate themselves in this discourse by praising their work tasks and opportunities within the IT industry. Most identified more readily with the term manong. Manong thus encapsulates Chinese programmers' difficult position, working hard on repetitive tasks under fast paced, highly monitored conditions. The term's direct reference to physical labour (i.e. farming) frames the idea that programmers think of their role in the immaterial economy as more closely related to menial, low level tasks than the rarefied, technical tasks supposed of those who work on computers. In this context, the manong's status as "knowledge" workers becomes an ironic insult, with the term diaosi used as a rallying point through which IT programmers vent their frustrations.

\section{Discussion and Implications}

Drawing on the concept of knowledge workers, this study explores the identity dynamics of manong in China. In conclusion, four themes concerning being an IT programmer have emerged from the empirical analysis. Table 1 shows an overview of the themes:

\begin{tabular}{|l|l|l|}
\hline $\begin{array}{l}\text { IT worker-related } \\
\text { theme }\end{array}$ & Characteristics & Links to identity \\
\hline $\begin{array}{l}\text { Knowledge work- } \\
\text { rs \& technology }\end{array}$ & $\begin{array}{l}\text { Professionalism, meritocrat, } \\
\text { identification }\end{array}$ & $\begin{array}{l}\text { A sense of "technical pride" is constructed through } \\
\text { expertise in computing languages and gendered } \\
\text { skills. Discourse on the rapid growth of the IT } \\
\text { industries contributes to this identification. } \\
\text { Knowledge workers perceive themselves as a } \\
\text { meritocracy. }\end{array}$ \\
\hline $\begin{array}{l}\text { Knowledge work- } \\
\text { ers \& liquidity }\end{array}$ & $\begin{array}{l}\text { Places, mobility, and inter- } \\
\text { nalized precarity }\end{array}$ & $\begin{array}{l}\text { Mobility and frequent job-hopping are "a normal } \\
\text { part of being a programmer". They are require- } \\
\text { ments for better development and chances. Work- } \\
\text { ers internalise the risk via a strong motivation to } \\
\text { succeed. }\end{array}$ \\
\hline $\begin{array}{l}\text { Knowledge work- } \\
\text { ers as manong }\end{array}$ & $\begin{array}{l}\text { Deskilling and panoptic con- } \\
\text { trol }\end{array}$ & $\begin{array}{l}\text { Much of their work is mechanical and unskilled. } \\
\text { Being a manong is a process of deskilling, hyper- } \\
\text { pressure and alienation. The "lively, friendly, and } \\
\text { harmonious" facade of the workplace creates } \\
\text { panoptic control of IT workers. }\end{array}$ \\
\hline $\begin{array}{l}\text { Knowledge work- } \\
\text { ers and Diaosi } \\
\text { discourse }\end{array}$ & $\begin{array}{l}\text { Diaosi discourse: a chal- } \\
\text { lenge of hegemony }\end{array}$ & $\begin{array}{l}\text { Diaosi discourse is constructed by low income, } \\
\text { poor capability, and uninspiring possibilities for } \\
\text { future advancement. It is a collective expression } \\
\text { that seeks self-expression and self-awareness. }\end{array}$ \\
\hline
\end{tabular}

Table 2: IT worker-related themes, characteristics, and links to identity dynamics

Some characteristics of knowledge workers identified in this study correspond to Virno and Hardt's concept of "less materialized" commodities, which are defined by their "cultural, informational or knowledgeable components" (Virno and Hardt 1996, 262). However, the identification as manong and diaosi amongst programmers addresses less "cultural, informational, knowledgeable" causes than physical, repetitive, and deskilling work that low level Chinese programmers have confronted in their work practices. Though Hardt and Negri (1994) insist that knowledge workers are not only a "select cadre of technical workers", but also "a massified quantity of cyborgs and labouring intelligentsia" (280), in our analysis, it would be a limitation to prioritise intelligence over manual work or vice versa. To echo the holistic conception of knowledge workers discussed in the introduction to this paper, our analysis considers knowledge workers' identity as composed of both digital and physical dimensions.

Our third research question focuses on how the experience of programmers in China confirms or extends the existing studies of knowledge labour. Besides supporting a more comprehensive definition of "knowledge workers" as championed by recent scholarship, our 
analysis of programmers' personal memoirs also interrogates the issues of survival, struggle and plight (See also: Fuchs 2014; Sandoval 2013). As Lazzarato (1996) has indicated, the working characteristics and arrangements that exist within the information society make it possible for new power relations to arise. As one of the social groups whose discursive power is marginalised within mainstream media, IT workers enact the manong and diaosi identities as an outlet for self-expression and a site for resistance.

According to Dong and Huang (2013), manong and diaosi are rallying calls in modern China and through these collective expressions, it is possible for knowledge workers to call attention to and challenge the highly exploitative components of their digitalised working processes. However, it remains to be seen as to whether these mainstream discourses can create a "genuine autonomous communication network" (McKercher and Mosco 2008, xxi) through which to challenge hegemonic structures and achieve meaningful and lasting changes within the (Chinese) IT industry.

Four themes concerning identification emerge from our cultural discourse analysis. They are: 1) technology and meritocracy 2) high mobility and precarity 3) identification as manong, and 4) diaosi discourse. The discourse of being an IT programmer is not a unitary one. It is interesting to find that the identity dynamics of IT workers in China are somewhat contradictory. On the one hand, new chances and expectations can be found by IT workers (such as their identification with technology, technical skills, and the advancement of the industry as a whole; as well as programmers' optimism toward mobility and precarity), while on the other, a process of reaffirmation of the traditional labouring process also takes place (seen in the complaints about deskilled, repetitive work, a perceived lack of promotion opportunities, and manong and diaosi expressions). In this context, the complexity of IT work culture becomes evident.

While parts of the manongs' working experience, such as liquid working conditions, overwork, and even the similarity of the "manong" and "code monkey" labels, form a common thread between extant profiles of software engineers in China and the West, there are several salient differences between the programmers featured in this study and their Western counterparts. Drawing on the example of programmers working at Google, Fuchs (2014) has described programmers in the West as a "labour aristocracy of highly paid, highly stressed workers" (264). Manong working in laborious and highly monitored conditions are likely to feel the same (if not more) stress, however, without the compensatory benefits of high pay, and, to some degree, high status. A salient point here is that small Chinese software companies exist at the base of the capital pyramid, situated at the farthest point from the end profits. While China's software products are mainly for the domestic market, the cycle of production is affected by international capital and globalisation. Working in small companies performing outsourced tasks for bigger companies, the value created by Chinese software engineers is reaped by either foreign capital or domestic Chinese capital. The code farmers' existence can then be seen as necessary to support the creation of surplus value for both Chinese and transnational companies, through unfair, highly exploitative labour that is integrated into the transnational production chain of large companies.

Finally, we need to ask: How can we make sense of these four themes of worker identity emerging from the respondents' narratives? What McKercher and Mosco (2008, xiv) have suggested is that the issues knowledge workers are confronting should be positioned into "the wider social totality of interconnected political, economic, social and cultural forces". Because the IT industries have established an exclusive, socially constructed discourse that focuses on economic development, innovation and knowledge (Fuchs 2014; Xiang 2007), this same ideological discourse meanwhile obscures the disenfranchisement, alienation and exploitation experienced by some IT workers. The fact that manong are at the lowest point of the hierarchy of software production means they gain little attention in overall discussions of IT and technology and can thus be easily overlooked by companies in favour of economic factors (Sandoval 2013). The highly individualised working conditions common to the IT industry further exacerbate feelings of alienation felt by manong. Beck and Beck-Gernsheim (2002) have noted that the increased institutionalisation and standardisation in modern companies enhances individualisation. According to Upadhya and Vasavi (2006), IT program- 
mers display such a pronounced sense of individualisation due to the lack of collective identity and the institutionalised working processes present in the IT industry. Most of the time, programmers have to make important decisions on their own in order to complete their work and projects within deadlines. Moreover, the specialisation inherent to IT companies constrains programmers within a limited set of professional skills, while prying into others' work conditions or salary is regarded as unprofessional and inappropriate.

People's communication practices can be shaped by their environment and vice versa. To some extent, IT workers' identification with technology, mobility, manong and diaosi is constructed through their communication practices. But these discourses also reflect the programmer's social reality. We argue that the four emerging themes identified of computer programmers do not occur independently but are rather integrated into: 1) the dominant ideological discourse that focuses on economic development and technology worship; and 2) the process of individualisation among IT programmers.

This does not mean that the four themes identified in this study are comprehensive in explaining the identity dynamics of IT programmers. Knowledge workers in the digital economy support a diverse range of meanings. This paper represents only one exploratory study of IT workers' identity in China. Broader issues like gender, class and hierarchy will continue to provide new insights for further research on knowledge workers with questions like: What do IT workers, as knowledge workers, mean to China? How do the "manong" and "code monkey" labels compare to one another? How can knowledge workers gain control of their subjectivity and connect with other international bodies of knowledge labour? Finding answers provides fertile ground for future research.

\section{References}

Arora, Ashish, V. S Arunachalam, Jai Asundi and Ronald Fernandes. 2001. The Indian Software Services Industry. Research Policy 30 (8): 1267-1287.

Barbrook, Richard. 1998. The Hi-Tech Gift Economy. First Monday, 3(12): 1-12. Accessed September 6, 2015. http://firstmonday.org/ojs/index.php/fm/article/viewArticle/631.

Bentham, Jeremy. 1791. Panopticon or the Inspection House. London: Sage.

Beck, Ulrich and Elisabeth Beck-Gernsheim. 2002. Individualization: Institutionalized Individualism and Its Social and Political Consequences. London: Sage.

Bell, Daniel. 1976. The Coming of the Post-industrial Society. The Educational Forum 40 (4): 574-579.

Boylorn, Robin. 2008. As Seen on TV: An Autoethnographic Reflection on Race and Reality Television. Critical Studies in Media Communication 25 (4): 413-433.

Carbaugh, Donal. 2007. Cultural Discourse Analysis: Communication Practices and Intercultural Encounters. Journal of Intercultural Communication Research 36 (3): 167-182.

Carbaugh, Donal, Timothy A Gibson and Trudy Milburn. 1997. A View of Communication and Culture: Scenes in an Ethnic Cultural Center and Private College. In Emerging Theories of Human Communication, edited by Branislav Kovačić, 1-24. Albany. NY: State University of New York Press.

CNNIC. 2014. Statistical Report on Internet Development in China. China Internet Network Information Center. Accessed 8 September, 2015. http://www1.cnnic.cn/IDR/ReportDownloads/201404/U020140417607531610855.pdf

Das, Gurchuran. 2001. India Unbound: A Personal Account of a Social and Economic Revolution from Independence to the Global Information Age. New York: Anchor.

Deetz, Stanley. 1995. Transforming Communication, Transforming Business: Building Responsive and Responsible Workplaces. New York: Hampton Press.

D'Costa, Anthony P. 2003. Capitalist Maturity and Corporate Responses to Liberalization: The Steel, Automobile, and Software Sectors in India. In Corporate Capitalism in Contemporary South Asia: Conventional Wisdoms and South Asian Realities, edited by Ananya Mukherjee Read, 106-133. Basingstoke: Palgrave Macmillan.

D' Mello, Marissa. 2006. Gendered Selves and Identities of Information Technology Professionals in Global Software Organizations in India. Information Technology for Development 12 (2): 131-158.

D'Mello, Marisa, and Sundeep Sahay. 2007. "I am kind of a nomad where I have to go places and places"... Understanding Mobility, place and Identity in Global Software Work from India. Information and Organization 17 (3): 162-192.

Dominguez, Daniel, Anne Beaulieu, Adolfo Estalella, Edgar Gómez, Bernt Schnettler and Rosie Read. 2007. Virtual Ethnography. Qualitative Social Research 8 (3): 3-7. 
Dong, Haijun and Qiping Huang. 2013. The Popularity of "Diaosi" and its Social Meaning. China Youth Study 1 (1): 5-8. (In Chinese).

Downey, Gary Lee, and Juan C. Lucena. 2005. National Identities in Multinational Worlds: Engineers and 'Engineering Cultures'. International Journal of Continuing Engineering Education and Life Long Learning 15 (3-6): 252-260.

Drucker, Peter. 1969. The Age of Discontinuity: Guidelines to Our Changing Society. New York: Harper \& Row.

Drucker, Peter. 1992. The New Society of Organizations. Harvard Business Review 70 (5): 95-104.

Edwards, Paul. 1997. The Closed World: Computers and the Politics of Discourse in Cold War America. Cambridge, MA: MIT Press.

Engels, Friedrich. 1892. The Development of Socialism from Utopia to Science. New York: Labor News Company.

Ensmenger, Nathan L. 2012. The Computer Boys Take Over: Computers, Programmers, and the Politics of Technical Expertise. Cambridge, MA: MIT Press.

Florida, Richard. 2002. The Rise of the Creative Class: And How it's Transforming Work, Leisure, Community and Everyday life. New York: Basic Books.

Florman, Samuel. 1996. The Existential Pleasures of Engineering. London: Macmillan.

Foucault, Michel. 1977. Discipline and Punish: the Birth of the Prison. Translated by Alan Sheridan. New York: Pantheon Books.

Fuchs, Christian. 2014. Digital Labour and Karl Marx. New York: Routledge.

Fuchs, Christian. 2015. Culture and Economy in the Age of Social Media. New York: Routledge. Fuller, Chris J., and Haripriya Narasimhan. 2007. Information Technology Professionals and the New-Rich Middle Class in Chennai (Madras). Modern Asian Studies 41 (1): 121-150.

Gartner. 2014. Annual Report of ICTs in China. Accessed 2 February, 2016. http://www.gartner.com

Hardt, Michael and Antonio Negri. 1994. Labour of Dionysus: A Critique of State-Form. Minneapolis, MN: University of Minnesota Press.

Hacker, Sally. 1989. Pleasure, Power and Technology: Some Tales of Gender, Engineering and the Cooperative workplace. Boston, MA: Unwin Hyman.

Hacker, Sally. 1990. "Doing it the Hard Way": Investigations of Gender and Technology, edited by Dorothy E. Smith and Susan M. Turner. Boston, MA: Unwin Hyman.

ledema, Rick, Carl Rhodes and Hermine Scheeres. 2005. Presencing Identity: Organizational Change and Immaterial Labour. Journal of Organizational Change Management 18 (4): 327-337.

Janz, Brian D, Jason A. Colquitt and Raymond A Noe. 1997. Knowledge Worker Team Effectiveness: The Role of Autonomy, Interdependence, Team Development, and Contextual Support Variables. Personnel Psychology 50 (4): 877-904.

Kelty, Christopher M. 2008. Two Bits: The Cultural Significance of Free Software. Durham: Duke University Press.

Kleinman, Daniel Lee and Steven P. Vallas. 2001. Science, Capitalism, and the Rise of the "Knowledge Worker": The Changing Structure of Knowledge Production in the United States. Theory and Society $30(4): 451-492$.

Lazzarato, Maurizio. 1996. Immaterial labour. In Radical Thought in Italy: A Potential Politics, edited by Paolo Virno and Michael Hardt, 132-146. Minneapolis, MN: University of Minnesota Press.

Levy, Steven. 2001. Hackers: Heroes of the Computer Revolution. New York: Penguin Books.

Li, Chaomin and Li Li. 2013. The Postmodern Discourse Analysis of "Diaosi". China Youth Study 1 (3): 13-16 (in Chinese).

Lindtner, Silvia. 2014. Hackerspaces and the Internet of Things in China: How Makers Are Reinventing Industrial Production, Innovation, and the Self. China Information 28 (2): 145-167.

Machlup, Fritz. 1962. The Production and Distribution of Knowledge in the United States. Princeton, $\mathrm{NJ}$ : Princeton University Press.

Maniam, Vegneskumar. 2014. The Memoir Method in Educational Research from an Australian Perspective. Qualitative Sociology Review 10 (3): 48-59. Accessed 6 September, 2015. http://www.qualitativesociologyreview.org/ENG/Volume30/QSR_10_3 Maniam.pdf

Marazzi, Christian. 2011. Capital and Affects: The Politics of the Language Economy. Translated by Giuseppina Mecchia. Cambridge, MA: MIT Press.

McKercher, Catherine, and Vincent Mosco. 2008. Knowledge Workers in the Information Society. Lanham, MD: Lexington Books.

Mellström, Ulf. 1995. Engineering Lives: Technology, Time and Space in a Male-centred World. Doctoral Thesis. Linköping: Linköping University. 
Ministry of Information Industry (MII). 2014. Zhongguo Dianzi Xinxi Chanye Tongji Nianjian (2014 Statistical Yearbook of Chinese Electronic Information Industry). Beijing: Publishing House of Electronics Industry.

Ministry of Industry and Information Technology (MIIT). 2013. Report of the Software Industry of China in 2014. Accessed February 23, 2016. http://www.miit.gov.cn/n1146312/n1146904/n1648374/index.html

Mosco, Vincent and Catherine McKercher. 2009. The Laboring of Communication: Will Knowledge Workers of the World Unite? Lanham, MD: Rowman \& Littlefield

Mukherjee, Sanjukta. 2008. Producing the Knowledge Professional: Gendered Geographies of Alienation in India's New High-Tech Workplace. In In an Outpost of the Global Economy: Work and Workers in India's Information Technology Industry, edited by Carol Upadyha and A.R. Vasavi, 5075. New Delhi: Routledge.

Murray, Fergus. 1993. A Separate Reality: Science, Technology and Masculinity. Gendered by Design. Gendered Design?: Information Technology And Office Systems, edited by Eileen Green, 6480. Boca Raton: CRC Press.

Richta, Radovan. 1969. Civilization at the Crossroads: Social and Human Implications of the Scientific and Technological Revolution. White Lains, NY: International Arts and Sciences Press.

Rushkoff, Douglas. 2010. Program or Be Programmed: Ten Commands for a Digital Age. New York: Or Books.

Sandoval, Marisol. 2013. Foxconned Labour as the Dark Side of the Information Age: Working Conditions at Apple's Contract Manufacturers in China. tripleC: Communication, Capitalism \& Critique 11 (2): 318-347.

Scott, Joy Denise. 2014. Memoir as a Form of Auto-Ethnographic Research for Exploring the Practice of Transnational Higher Education in China. Higher Education Research \& Development 33 (4): 757-768.

Shirky, Clay. 2010. Cognitive Surplus: Creativity and Generosity in a Connected Age. London: Penguin.

Smythe, Dallas W. 1977. Communications: Blindspot of Western Marxism. Canadian Journal of Political and Social Theory 1 (3): 1-27.

Terranova, Tiziana. 2004. Network Culture: Politics for the Information Age. London: Pluto Press.

Thomas, Douglas. 2002. Hacker Culture. Minneapolis, MN: University of Minnesota Press.

Upadhya, Carol and A.R. Vasavi. 2006. Work, Culture, and Sociality in the Indian IT Industry: A Sociological Study. Indo-Dutch Programme for Alternatives in Development. Accessed 6 September, 2015.

http://www.unikassel.de/ tduermei/iksa/readerengl/addtext $\% 2013$ Updadhya $\% 202006 \% 20$ Work, $\% 2$ 0Culture\%20and\%20Sociality-1.pdf

Valk, Reimara and Vasanthi Srinivasan. 2011. Work-Family Balance of Indian Women Software Professionals: A Qualitative Study. IIMB Management Review 23 (1): 39-50.

Virno, Paolo and Michael Hardt. 1996. Radical Thought in Italy: A Potential Politics. Minneapolis, MN: University of Minnesota Press.

Weber, Steve. 2004. The Success of Open Source. Cambridge, MA: Harvard University Press.

Witteborn, Saskia. 2008. Identity Mobilization Practices of Refugees: The Case of Iraqis in the United States and the War in Iraq. Journal of International and Intercultural communication 1 (3): 202-220.

Xia, Bingqing. 2014. Digital Labour in Chinese Internet Industries. triple: Communication, Capitalism \& Critique 12 (2): 668-693.

Xiang, Biao. 2007. Global "Body shopping": An Indian Labour System in the Information Technology Industry. Princeton, NJ: Princeton University Press.

Yue Bing. 2015. An Analysis of China's Software Industry Cluster. Modern Economy 3 (18): 36-37. (In Chinese)

\section{About the Authors}

Sophie Sun Ping

Sophie is a PhD Candidate in the School of Journalism and Communication at The Chinese University of Hong Kong. Her research interests are ICTs, new media and digital labour. 
Michelangelo is currently undertaking doctoral research at Curtin University, examining the relationship between online and offline travel texts. His research interests include: tourism, social media and community studies. 